\title{
Obtenção de espumas cerâmicas a partir de resíduo da terra diatomácea e ignimbrita pelo método de réplica
}

\section{(Obtaining ceramic foams from the diatomaceous earth waste and ignimbrite by replica method)}

\author{
K.Z.Huanca, A. B.de A. Nunes \\ Departamento de Engenharia Hidráulica e Ambiental, Universidade Federal do Ceará \\ abarbara@deha.ufc.br,karzuha28@gmail.com
}

\begin{abstract}
Resumo
As cerâmicas celulares são materiais frágeis de elevada porosidade e área superficial. O grande interesse por esta classe de materiais está relacionado às suas propriedades específicas e a sua permeabilidade com substâncias líquidas e gasosas. O objetivo principal deste trabalho foi desenvolver um suporte cerâmico poroso a partir de resíduo da terra diatomácea e ignimbrita pelo método de réplica a fim de atenuar os poluentes emitidos pela queima de tijolos e telhas provenientes da indústria da cerâmica vermelha. Para a fabricação do suporte cerâmico foram preparadas espumas cerâmicas pelo método da réplica. Para sua obtenção foi usado resíduo da terra diatomácea coletado em uma indústria cervejeira, ignimbrita (rocha vulcânica) e, como aglomerante, bentonita de Boa Vista (PB). Foram preparadas quatro formulações com duas variáveis, tamanho de grão e composição. Para analisar a estrutura morfológica do suporte cerâmico foram realizados ensaios de absorção de água, massa específica aparente, porosidade e microscopia eletrônica de varredura. Após a aplicação do suporte cerâmico em uma indústria cerâmica, observou-se uma redução de material particulado cujos valores ficaram dentro dos padrões estabelecidos pela Resolução n 382/2006 do CONAMA. Palavras-chave: espumas cerâmicas, poluição do ar.
\end{abstract}

\begin{abstract}
Cellular ceramics are brittle materials of high porosity and surface area. The great interest in this class of materials is related to their specific properties and permeability to liquid and gaseous substances. In this study, ceramic foams were prepared by replication method in order to produce the ceramic support. The aim of this study was to develop a porous ceramic support from residue of diatomaceous earth and ignimbrite by replication method to mitigate the pollutants emitted by the burning of bricks and tiles from the clay industry. Thus, diatomaceous earth residue collected in a brewing industry, ignimbrite, a volcanic rock, and bentonite (as a binder) from Boa Vista city (PB) were used to obtain such ceramic support. Four formulations were prepared with two variables, size of grain and composition. Tests of water absorption, apparent density, porosity, and scanning electron microscopy were conducted to analyze the morphological structure of the ceramic support. Applying the ceramic support in a ceramic industry, the reduction of particulate materials was in agreement with the standards established by the Resolution No. 382/2006 of CONAMA.
\end{abstract}

Keywords: ceramic foam, air pollution.

\section{INTRODUÇÃO}

Nos últimos anos, diversas técnicas de preparação de cerâmicas porosas estão sendo pesquisadas, buscando a obtenção de materiais com geometria complexa, microestrutura projetada e sem a necessidade da etapa de usinagem (redução de custos) [1]. Cerâmicas apresentam boa estabilidade dimensional, são resistentes ao desgaste e à compressão e estáveis em ambientes ácidos [2]. As cerâmicas porosas pertencem à classe de materiais caracterizados por uma rede tridimensional de poros dispostos de forma regular e interconectados entre si através de canais [3].
Existem vários métodos e técnicas de processamento para a fabricação de cerâmicas celulares que permitem ajustar a porosidade, a distribuição, o tamanho e a morfologia dos poros, entre as quais podem ser citadas: queima de partículas orgânicas, gel casting, direct foaming, réplica, etc. [1]. Entre todos esses processos de fabricação, o método da réplica tem sido o de maior utilização. Este método foi patenteado em 1963 por Scwartzwalder e Somers; desde então, a réplica de esponjas poliméricas passou a ser o método mais popular na produção de cerâmica porosa e hoje é amplamente utilizada na indústria cerâmica para fabricação de filtros cerâmicos, na filtração de metais fundidos e gases a altas temperaturas. 
Este sucesso é atribuído principalmente ao baixo custo, simplicidade e flexibilidade do método [4]. Neste método, uma esponja polimérica altamente porosa, geralmente poliuretano, é impregnada em uma suspensão cerâmica até o preenchimento dos poros internos, sendo que após a secagem e mediante um tratamento térmico, que visa à queima, eliminação do material orgânico (esponja) e a sinterização do material cerâmico, resultam em um material com porosidade aberta e microestrutura semelhante à esponja precursora. Cerâmicas porosas obtidas por este método podem chegar a uma porosidade aberta total na faixa de $40 \%$ a $95 \%$ e são caracterizadas por uma estrutura reticulada de poros altamente interligados com tamanhos entre $200 \mu \mathrm{m}$ e $3 \mathrm{~mm}$. Esta interconectividade dos poros aumenta a permeabilidade dos fluidos e gases através da estrutura porosa $[1,4]$.

A terra diatomácea é uma rocha de origem sedimentar e é um material muito fino, de estrutura porosa, rica em sílica amorfa hidratada, constituída essencialmente por carapaças de algumas diatomáceas, apresentando baixa condutividade térmica, elevado ponto de fusão, elevada área superficial, baixa densidade e essencialmente inerte à maioria dos líquidos e gases químicos [5]. A terra diatomácea, também chamada de diatomita, é usada pelas indústrias cervejeiras durante o processo de clarificação da cerveja, sendo posteriormente descartada como resíduo industrial. Uma empresa de grande porte de produção de cerveja pode gerar aproximadamente $30.000 \mathrm{~kg} / \mathrm{mês}$ deste resíduo [6]. Este trabalho tem como objetivo principal desenvolver um suporte cerâmico poroso a partir de resíduo da terra diatomaçea e ignimbrita pelo método de réplica a fim de atenuar os poluentes emitidos pela queima de tijolos e telhas provenientes da indústria da cerâmica vermelha.

\section{PROCEDIMENTO EXPERIMENTAL}

Para a preparação e aplicação do suporte cerâmico foram realizadas as seguintes etapas: caracterização química e mineralógica das matérias-primas; caracterização química da diatomita após o tratamento térmico; preparação do suporte cerâmico; caracterização física e mecânica do suporte cerâmico; aplicação do suporte cerâmico na indústria cerâmica.

\section{Matérias-primas}

Neste trabalho foram utilizadas três matérias-primas: terra diatomácea, ignimbrita e a bentonita. A terra diatomácea foi doada como resíduo por uma indústria cervejeira localizada no Ceará. Foi obtida com alto teor de umidade, o qual foi reduzido através da secagem à temperatura ambiente, em torno de $30^{\circ} \mathrm{C}$, que foi chamada de diatomita saturada. Posteriormente foi submetida à calcinação em um forno mufla $\left(800^{\circ} \mathrm{C}, 2 \mathrm{~h}\right)$ para eliminação da matéria orgânica e impurezas absorvidas durante a etapa de filtração, a qual foi chamada de diatomita tratada. A ignimbrita é uma pedra vulcânica da cor branca, de alta dureza. Foi extraída na pedreira de Añashuayco, situada ao oeste de Cerro Colorado no nordeste da cidade de Arequipa - Peru. Devido à sua composição química, tem uma elevada estabilidade ao ataque químico. A bentonita disponível utilizada neste trabalho foi doada por uma indústria cerâmica da Paraíba. Para análise da composição química e minerológica das matérias-primas, foram realizados os ensaios de espectroscopia de fluorescência de raios X (FRX) e difração de raios X (DRX).

\section{Preparação do suporte cerâmico}

Para a fabricação do suporte cerâmico aplicou-se o método de réplica, o qual consiste na impregnação de uma esponja polimérica com uma suspensão cerâmica, seguida de um tratamento térmico, que visa à queima e eliminação do material poliuretano (esponja) e também a sinterização do esqueleto cerâmico [4]. Para o presente trabalho foi utilizada como matriz do suporte cerâmico uma esponja de poliuretano (PU), de densidade $16 \mathrm{~kg} / \mathrm{m}^{3}$ com dimensões de $9 \mathrm{~cm}$ x $12 \mathrm{~cm}$ x $2 \mathrm{~cm}$ (Fig. 1).

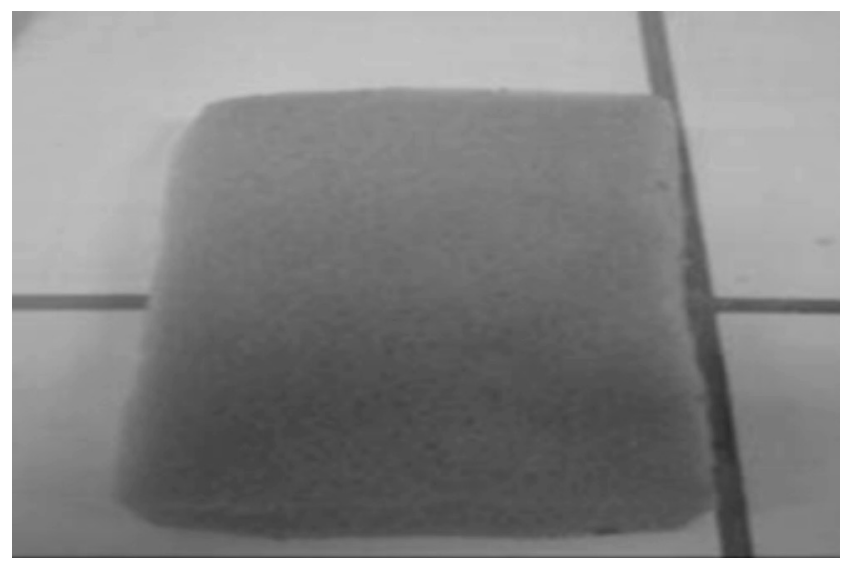

Figura 1: Imagem da esponja polimérica de poliuretano.

[Figure 1: Images of polymeric sponge of polyurethane.]

Para a preparação das suspensões cerâmicas, foram realizadas algumas misturas variando a proporção da massa de terra diatomácea utilizada (10\% e 16\%), assim como a massa de ignimbrita (10\% e $16 \%$ ), usando como aglomerante a bentonita, na proporção de $2 \%$ em massa e como solvente a água destilada na proporção de $72 \%$ do total de massa para todas as formulações. O tamanho dos grãos utilizados nas formulações foi de 200 mesh $(0,074 \mathrm{~mm})$ e 400 mesh $(0,033 \mathrm{~mm})$. Na Tabela I são apresentadas as misturas utilizadas nas formulações. Após o preparo das suspensões, estas foram homogeneizadas (10 a 15 min) a fim de se obter uma suspenção cerâmica com uma viscosidade aceitável para a impregnação da suspenção na esponja polimérica. Em seguida, as esponjas poliméricas (PU) foram impregnadas manualmente com a suspensão cerâmica. $\mathrm{O}$ excesso da suspensão foi retirado manualmente e a secagem foi realizada na estufa a $100{ }^{\circ} \mathrm{C}$ por aproximadamente $24 \mathrm{~h}$. As esponjas impregnadas 
passaram pelo processo de sinterização a $1100{ }^{\circ} \mathrm{C}$ em forno mufla (Jung, LF0312), por $60 \mathrm{~min}$; a pirólise (queima) do polímero foi feita a $400{ }^{\circ} \mathrm{C}$ por $60 \mathrm{~min}$. Após o tratamento térmico, obtiveram-se os filtros cerâmicos (espumas cerâmicas, Fig. 2).

Tabela I - Formulações das misturas da suspensão cerâmica. [Table I - Formulations of mixtures of ceramic suspension.]

\begin{tabular}{|c|c|c|c|c|}
\hline Materiais & $\mathrm{F} 1$ & $\mathrm{~F} 2$ & F3 & F4 \\
\hline Diatomita & $16 \%$ & $10 \%$ & $16 \%$ & $10 \%$ \\
\hline $\begin{array}{l}\text { Ignimbrita } \\
\text { Peneira }\end{array}$ & $\begin{array}{c}10 \% \\
\# 200 \\
(0,074 \mathrm{~mm})\end{array}$ & $\begin{array}{c}16 \% \\
\# 200\end{array}$ & $\begin{array}{c}10 \% \\
\# 400 \\
(0,033 \mathrm{~mm})\end{array}$ & $\begin{array}{r}16 \% \\
\# 400\end{array}$ \\
\hline
\end{tabular}

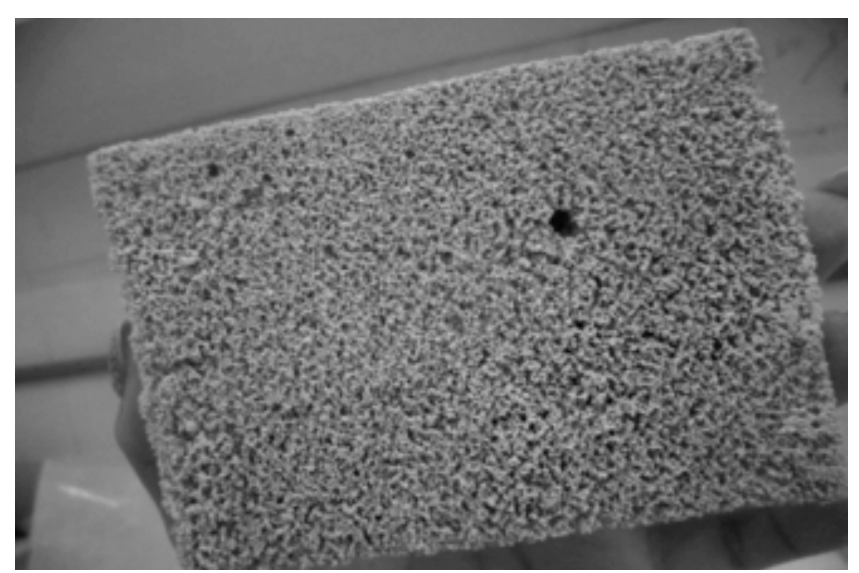

Figura 2: Imagem do filtro cerâmico.

[Figure 2: Image of ceramic filter.]

Após a obtenção da espuma cerâmica, foram realizadas as análises para a sua caracterização física e microestrutural: absorção de água (AA), massa especifica aparente (MEA), porosidade (PA) e microscopia eletrônica de varredura (MEV). Os filtros foram submetidos a ensaios de resistência à compressão axial utilizando corpos de prova cilíndricos com aproximadamente $30 \mathrm{~mm}$ de diâmetro e 60 $\mathrm{mm}$ de altura. Os corpos de prova foram submetidos a uma compressão axial e levados à ruptura em uma prensa com uma velocidade de deformação constante de $5 \mathrm{~mm} / \mathrm{min}$.

\section{Medição do material particulado com o uso da esponja cerâmica}

A medição do material particulado foi feita pelo SENAI (Serviço Nacional de Aprendizagem Industrial) utilizando o instrumento CIPA, coletor isocinético de poluentes atmosféricos. A referida medição foi feita em uma indústria de cerâmica vermelha no município de Russas, Ceará, que possui um forno intermitente, tipo paulistinha, com uma capacidade de produção 750 milheiros por mês de telhas, com um consumo aproximado de 900 a $950 \mathrm{~m}^{3}$ de lenha. As medições foram realizadas antes e depois do uso do suporte cerâmico.

\section{RESULTADOS E DISCUSSÃO}

Caracterização química e mineralógica das matériasprimas

A Tabela II apresenta os resultados da composição química determinada por espectroscopia de fluorescência de raios $\mathrm{X}$ das amostras. Observa-se que a amostra de bentonita apresentou um maior percentual de óxidos de $\mathrm{SiO}_{2}$ $(62,15 \%), \mathrm{Al}_{2} \mathrm{O}_{3}(18,53 \%)$ e $\mathrm{Fe}_{2} \mathrm{O}_{3}(10,93 \%)$. Observa-se também que o teor de $\mathrm{Na}_{2} \mathrm{O}(1,84 \%)$ é maior do que $\mathrm{CaO}$ $(0,98 \%)$, o que indica tratar-se de uma bentonita sódica. A amostra da ignimbrita apresentou um teor de $73 \%$ de $\mathrm{SiO}_{2}$, classificando-a como uma rocha ácida, devido ao seu porcentual de $\mathrm{SiO}_{2}$. Na sua caracterização foram detectados óxidos fundentes $\left(\mathrm{CaO}, \mathrm{K}_{2} \mathrm{O}, \mathrm{Na}_{2} \mathrm{O}\right.$ e $\left.\mathrm{MgO}\right)$, os quais têm a função de diminuir a temperatura de formação de fase líquida durante a etapa de sinterização e favorecem a formação de fase vítrea [3]. A amostra de diatomita apresentou uma elevada quantidade de $\mathrm{SiO}_{2}(91 \%)$. O valor comumente encontrado varia de $80 \%$ a $90 \%$, o que corrobora com os valores encontrados nas indústrias que usam a diatomita na etapa da filtração, onde além do elevado percentual de sílica também apresenta baixos percentuais de $\mathrm{CaO}, \mathrm{MgO}, \mathrm{Al}_{2} \mathrm{O}_{3}$, $\mathrm{Fe}_{2} \mathrm{O}_{3}$ e demais impurezas [5, 7].

Tabela II - Composição química das matérias-primas. [Table II - Chemical composition of raw materials.]

\begin{tabular}{|c|c|c|c|}
\hline Óxido & $\begin{array}{c}\text { Bentonita } \\
(\%)\end{array}$ & $\begin{array}{c}\text { Ignimbrita } \\
(\%)\end{array}$ & $\begin{array}{c}\text { Diatomita } \\
\text { saturada (\%) }\end{array}$ \\
\hline $\mathrm{SiO}_{2}$ & 62,15 & 73,4 & 91,02 \\
\hline $\mathrm{Al}_{2} \mathrm{O}_{3}$ & 18,53 & 9,52 & 1,23 \\
\hline $\mathrm{Fe}_{2} \mathrm{O}_{3}$ & 10,93 & 3,25 & 4,40 \\
\hline $\mathrm{MgO}$ & 2,50 & - & - \\
\hline $\mathrm{Na}_{2} \mathrm{O}$ & 1,84 & 5,69 & - \\
\hline $\mathrm{K}_{2} \mathrm{O}$ & 1,33 & 5,18 & 0,59 \\
\hline $\mathrm{TiO}_{2}$ & 1,16 & 0,45 & - \\
\hline $\mathrm{CaO}$ & 0,98 & 2,08 & 1,99 \\
\hline $\mathrm{Cl}$ & 0,25 & 0,10 & 0,06 \\
\hline $\mathrm{SO}_{3}$ & 0,12 & - & 0,44 \\
\hline $\mathrm{P}_{2} \mathrm{O}_{5}$ & 0,11 & - & - \\
\hline $\mathrm{ZnO}$ & - & - & 0,23 \\
\hline $\mathrm{SrO}$ & 0,03 & 0,16 & - \\
\hline $\mathrm{Rb}_{2} \mathrm{O}$ & 0,01 & 0,02 & - \\
\hline $\mathrm{MnO}$ & - & 0,11 & - \\
\hline
\end{tabular}

Caracterização química da diatomita após tratamento térmico

A Tabela III apresenta os dados da diatomita saturada e após o tratamento térmico. Os resultados mostraram 
diminuição de $\mathrm{SiO}_{2}(1,08 \%)$ na amostra tratada, com respeito à diatomita saturada, e aumentos nos teores de $\mathrm{CaO}, \mathrm{K}_{2} \mathrm{O}$, $\mathrm{Al}_{2} \mathrm{O}_{3}$ e $\mathrm{Fe}_{2} \mathrm{O}_{3}$. A porcentagem de $\mathrm{Fe}_{2} \mathrm{O}_{3}$ na diatomita saturada foi de $4,40 \%$ e da diatomita tratada de $5,11 \%$; esta diferença deve-se à oxidação do ferro durante o processo do tratamento térmico, dando-lhe uma coloração rosa à diatomita tratada. A composição química da terra diatomácea calcinada tem coloração rosa ou cinza. A coloração rosa é em função da oxidação do ferro presente [5]. Ensaios por perda de fogo para a diatomita tratada apresentaram perda de massa em média de $13 \%$, indicando que a quantidade de matéria orgânica presente na diatomita saturada é alta e pode estar relacionada à presença de componentes voláteis (hidroxilas, matéria orgânica, etc.).

Tabela III - Composição química da diatomita depois do tratamento térmico.

[Table III - Chemical composition of the diatomite after heat treatment.]

\begin{tabular}{cc}
\hline Óxido & $\begin{array}{c}\text { Diatomita tratada } \\
(\%)\end{array}$ \\
\hline $\mathrm{SiO}_{2}$ & 89,94 \\
$\mathrm{Al}_{2} \mathrm{O}_{3}$ & 1,59 \\
$\mathrm{Fe}_{2} \mathrm{O}_{3}$ & 5,11 \\
$\mathrm{~K}_{2} \mathrm{O}$ & 0,69 \\
$\mathrm{CaO}$ & 2,10 \\
$\mathrm{SO}_{3}$ & 0,33 \\
$\mathrm{ZnO}$ & 0,20 \\
\hline
\end{tabular}

Caracterização física do suporte cerâmico

Os resultados da caracterização física do suporte cerâmico estão apresentados na Tabela IV para as quatro formulações realizadas conforme descriminado no procedimento experimental. Observa-se que as formulações que apresentam maior porcentagem de absorção de água são as que têm em sua composição maior quantidade de diatomita (F1 e F3). Comparando as quatro formulações, a que apresentou maior percentual de absorção de água foi a formulação F3 a qual tem menor tamanho de grão, menor quantidade de ignimbrita e maior quantidade de diatomita, absorvendo três vezes o seu peso úmido. A formulação que apresenta maior porcentual de massa específica aparente é a F2, o que se deduz que é devido à quantidade de ignimbrita que apresenta na sua composição uma maior quantidade de minerais. Observa-se que os valores de porosidade aparente encontrados nas formulações correspondem, aproximadamente, a uma faixa que varia de 79 a $81 \%$. A porosidade aumenta devido ao tamanho do grão e à quantidade de diatomita presente na sua composição, indicando a influência da porosidade natural que a diatomita apresenta em sua estrutura.

Tabela IV - Resultados do ensaio de absorção de água (AA), massa específica aparente (MEA) e porosidade aparente (PA) do suporte cerâmico sinterizado.

[Table IV - Test results for water absorption (AA), apparent bulk density (MEA) and apparent porosity (PA) of the sintered ceramic support.]

\begin{tabular}{ccccccc}
\hline Amostra & $\begin{array}{c}\text { Massa } \\
\text { seca }(\mathrm{g})\end{array}$ & $\begin{array}{c}\text { Massa } \\
\text { úmida } \\
(\mathrm{g})\end{array}$ & $\begin{array}{c}\text { Massa } \\
\text { imersa } \\
(\mathrm{g})\end{array}$ & $\begin{array}{c}\text { AA } \\
(\%)\end{array}$ & $\begin{array}{c}\text { MEA } \\
\left(\mathrm{g} / \mathrm{cm}^{3}\right)\end{array}$ & $\begin{array}{c}\text { PA } \\
(\%)\end{array}$ \\
\hline F1 & 25,30 & 82,95 & 11,63 & 228,1 & 0,358 & 80,69 \\
F2 & 26,41 & 78,83 & 13,16 & 198,9 & 0,403 & 79,76 \\
F3 & 25,25 & 102,7 & 7,88 & 306,8 & 0,278 & 81,62 \\
F4 & 25,97 & 85,58 & 13,15 & 221,3 & 0,367 & 81,06 \\
\hline
\end{tabular}

\section{Resistência dos suportes cerâmicos}

A Tabela V apresenta os resultados de ensaio de compressão, em termos de tensão de esmagamento, comparando as quatro formulações. A Formulação F4 foi a que apresentou maior resistência à compressão. Durante o ensaio teve uma deformação constante até a ruptura. De acordo os resultados obtidos na caracterização física e mecânica das formulações, foi selecionado o suporte da formulação F4, por apresentar a maior resistência à compressão. Em relação à porosidade, a formulação F4 obteve o segundo maior valor. Destaca-se que o aumento na porosidade influencia diretamente na resistência mecânica do material [4].

\section{Microscopia eletrônica de varredura}

A análise por microscopia eletrônica de varredura (MEV) foi realizada no suporte da formulação F4. O

Tabela V - Resultados do ensaio de compressão para diferentes formulações.

[Table V-Results of compression test for different formulations.]

\begin{tabular}{cccccc}
\hline & \multicolumn{2}{c}{ Tamanho de grão } \\
Peneira & mm & $\begin{array}{c}\text { Fração de diatomita } \\
(\%)\end{array}$ & $\begin{array}{c}\text { Fração de ignimbrita } \\
(\%)\end{array}$ & $\begin{array}{c}\text { Resistência } \\
(\mathrm{MPa})\end{array}$ \\
\hline F1 & $\# 200$ & 0,074 & 16 & 10 & 0,11 \\
F2 & $\# 200$ & 0,074 & 10 & 16 & 0,36 \\
F3 & $\# 400$ & 0,033 & 16 & 10 & 0,77 \\
F4 & $\# 400$ & 0,033 & 10 & 16 & 0,80 \\
\hline
\end{tabular}


resultado mostrou a presença de esqueletos de diatomáceas com uma estrutura morfológica bem definida tipo circular e com porosidade em forma radial (Fig. 3). Na Fig. 4 observase a formação de dois poros abertos separados por uma parede cerâmica bem definida, interconectados entre si.

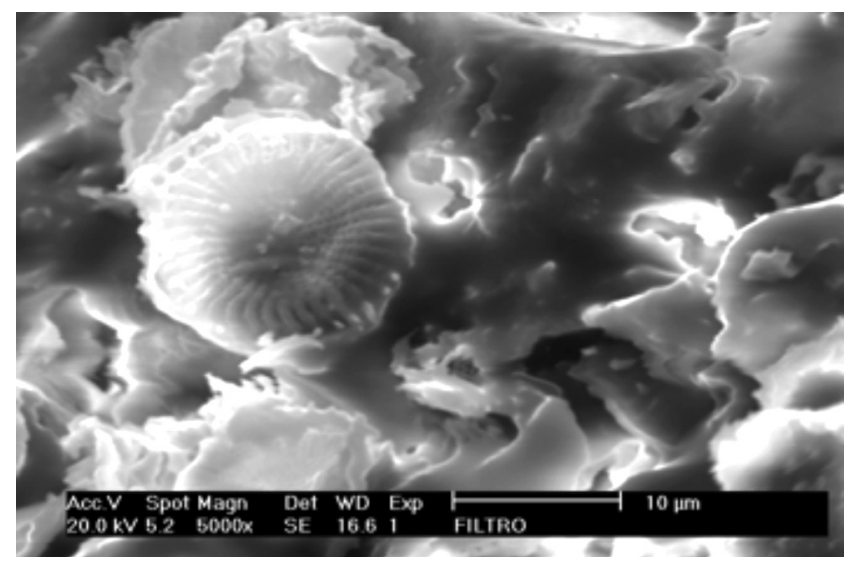

Figura 3: Imagem de MEV do suporte cerâmico.

[Figure 3: SEM image of ceramic support.]

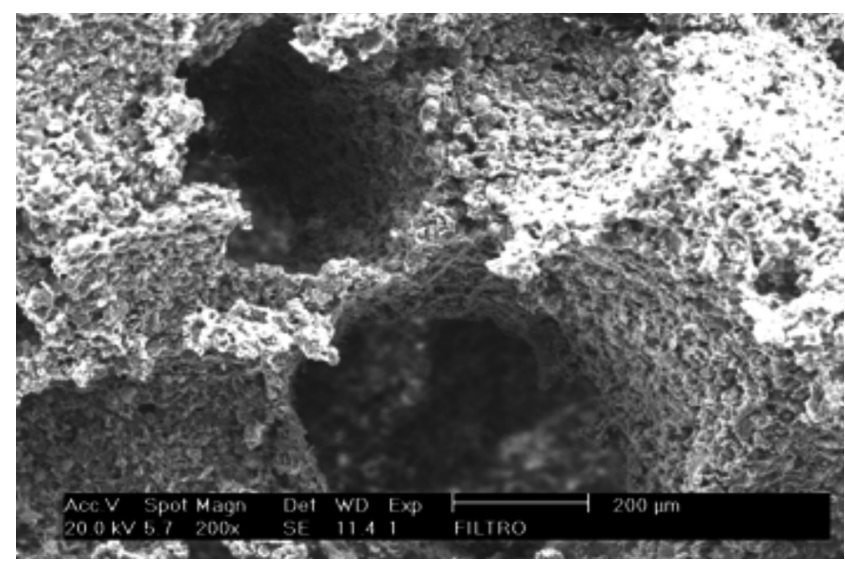

Figura 4: Micrografia da estrutura cerâmica.

[Figure 4: Micrograph of the ceramic structure.]

\section{Medição do material particulado}

Primeiro foram realizadas medições sem o suporte

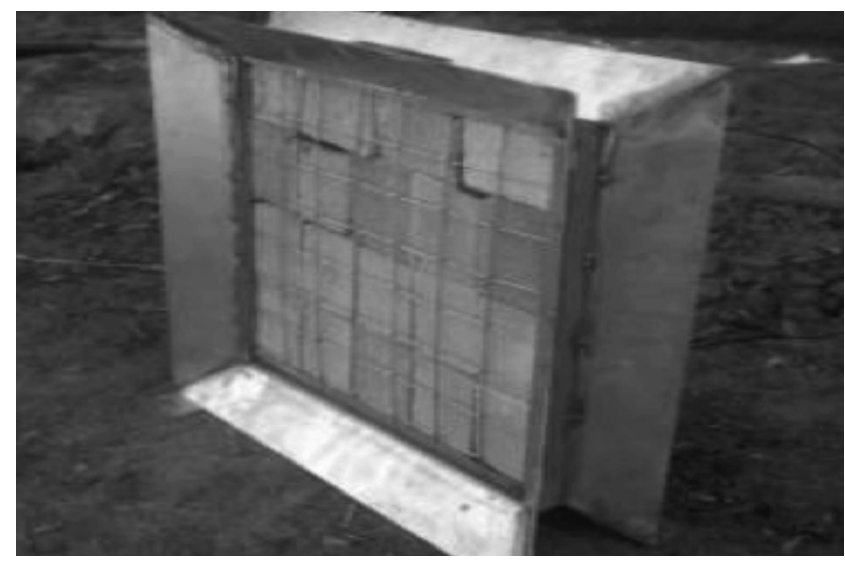

Figura 5: Estrutura metálica para os suportes cerâmicos. [Figure 5: Metallic structure for ceramic supports.] cerâmico na chaminé, a uma distância de $6 \mathrm{~m}$ do topo da chaminé. Esta medição foi feita com objetivo de quantificar a concentração de material particulado emitida pela indústria de cerâmica vermelha. Foram feitas três medições, perfazendo um total de $60 \mathrm{~min}$ por medição, totalizando $3 \mathrm{~h}$. Em um segundo momento, foi utilizado uma estrutura metálica onde foram colocados 19 suportes cerâmicos (Fig. 5). A estrutura metálica foi inserida no canal que dá acesso à chaminé da indústria cerâmica. $\mathrm{O}$ valor obtido de material particulado sem o suporte cerâmico foi de 1517,64 $\mathrm{mg} / \mathrm{N} \cdot \mathrm{m}^{3}$ e com o suporte cerâmico foi de $231,85 \mathrm{mg} / \mathrm{N} \cdot \mathrm{m}^{3}$. Desta forma, a remoção obtida foi de aproximadamente $85 \%$, estando desta forma dentro dos padrões estabelecidos pela Resolução n 382/2006 do CONAMA [8].

\section{CONCLUSÃO}

O aproveitamento de resíduos constitui um assunto de grande relevância nos dias atuais. Este trabalho utilizou uma mistura composta por terra diatomácea, que é um resíduo gerado pela indústria cervejeira, rocha vulcânica (ignimbrita), bentonita e água com o objetivo de produzir filtros cerâmicos pelo método da réplica para a retenção de material particulado proveniente de indústria cerâmica. A formulação escolhida para a elaboração do suporte cerâmico foi a F4 (10\% de diatomita, 16\% de bentonita, $2 \%$ de bentonita, $72 \%$ de água e peneira 400 mesh). Através do uso do suporte cerâmico selecionado, obteve-se uma redução de material particulado em aproximadamente $85 \%$, estando dentro dos limites estabelecidos pela Resolução no 382/2006 do CONAMA [8]. Tais resultados indicam o uso potencial do suporte cerâmico desenvolvido neste trabalho para a redução de poluentes provenientes da indústria da cerâmica vermelha. Destaca-se que o material particulado na atmosfera pode acarretar danos à saúde do homem e as iniciativas que busquem a minimização deste impacto ambiental devem ser incentivadas visando mitigar os problemas relacionados à poluição do ar.

\section{REFERÊNCIAS}

[1] R.C.O. Romano, V.C. Pandolfelli, Cerâmica 52 (2006) 213. [2] A.L.R. Pires, A.C.K. Bierhalz, A.M. Morae, Quím. Nova 38 (2015) 957.

[3] R.P. de A. Souza. Diss. Mestrado, Coord. Pós-grad. Ciências dos Materiais. Univ. Fed. Rio Grande do Norte, Natal (2011).

[4] K. Donadel, J.M. Gomes, C.R. Rambo, D. Hotza, A.P.N. Oliveira, Exacta 6 (2008) 41.

[5] P.A. Pimentel, A.A. Paccola, Rev. Energia Agricultura 22 (2007) 69.

[6] M.R. Goulart, C.B. Silveira, M.L. Campos, E.J.A. Almeida, S. Manfredi, A.F. Oliveira, Quím. Nova 34 (2011) 625.

[7] P.L.B. Silva, L.D.A. de Sousa, V. da S. Pinheiro, E. Harima, J.Y.P. Leite, Holos 3 (2009) 52.

[8] CONAMA, RESOLUÇÃO N. 382 (2006).

(Rec. 21/05/2015, Rev. 18/09/2015, 06/10/2015, Ac. $11 / 10 / 2015)$ 